\title{
THE GROWTH RATE OF VERRUCA STROEMIA (O. MÜLLER)
}

\author{
BY H. BARNES \\ The Marine Station, Millport, Scotland
}

(Text-figs. I and 2)

The growth rate under both natural and experimental conditions of several littoral and sublittoral barnacles has recently been dealt with in some detail (Barnes \& Powell, 1953, q.v. for earlier references; Barnes, 1952-53; Barnes \& Barnes, I954; Crisp, I954; Barnes \& Barnes, I956; Barnes, 1956). No comparable data for Verruca stroemia are reported in the literature.

Although V. stroemia has been reported from the Red Sea (Darwin, I854), the Adriatic (Kolosvary, 1947), and even the Indian Ocean (Nilsson-Cantell, 1938), the major area of its distribution is along the eastern Atlantic coasts of Europe from Spain to Finmark (for a review see Broch, I924). In addition, Stephensen (1929, 1933) states that it is found in the coastal waters of Iceland, Greenland and the Faroes (see also Weltner, 1900, and Schaper, 1922). The species appears to be absent from the western Atlantic. Although recorded from a depth of $548 \mathrm{~m}$ by Weltner (1900), it is most common on relatively shallow banks and rough inshore grounds, and it extends into the lowest parts of the intertidal zone. According to Broch (1924) it is moderately euryhaline, but Schaper (1922) states that it does not occur in the Baltic Sea. In the Clyde Sea Area it is widely distributed on suitable stony ground from the lower littoral to deeper water and grows on crustaceans and molluscs. Although Broch considered the species to be lusitanian-boreal in character, with extensions into the Arctic, its breeding behaviour (as far as is known) suggests a cold-water origin; like many other boreo-arctic species, it has a single major brood each year that is liberated in the early spring.

\section{THE MATERIAL AND METHODS}

In previous studies on both Balanus and Chthamalus spp. the rostro-carinal axis along the base has been measured, but because of asymmetry this is less satisfactory with Verruca stroemia. The longest diameter at the base has, therefore, been measured and for brevity will be termed the length. For the small animals a binocular microscope with low-power objective and scaled ocular was used, and for the large, a measuring microscope with vernier attachment. 
Animals were collected at an extreme low-tide level. For the estimation of annual growth under natural conditions large numbers of animals were measured and the results analysed with the help of probability paper. In order to estimate growth rates under conditions similar to those used for other species, stones bearing individuals well separated from each other were drilled

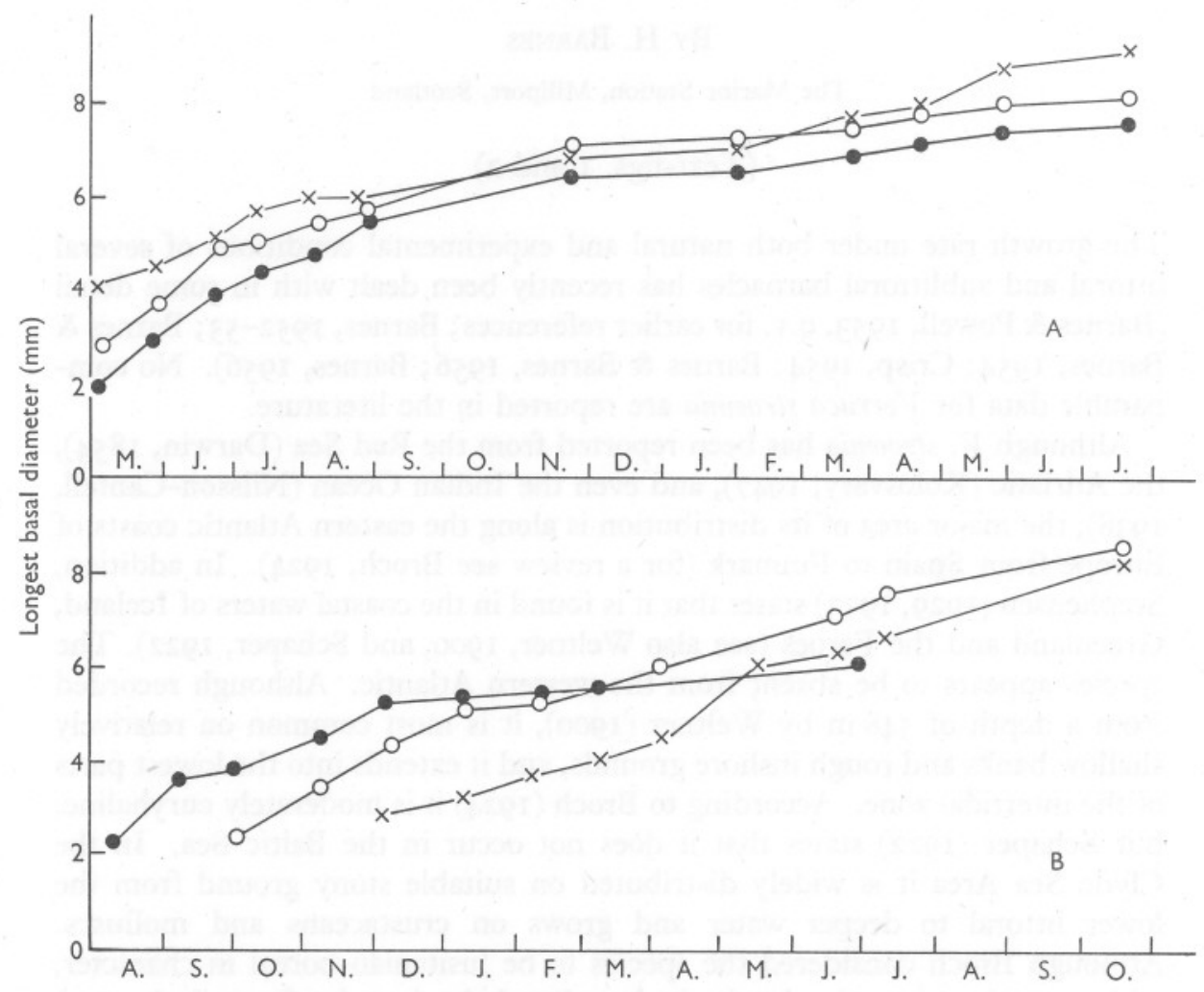

Fig. I. Growth of Verruca stroemia over two fifteen-month periods under conditions of continuous immersion. Animals cleaned at each inspection. Exposures made throughout year. A, May I955 to July I956; - Series $a$; ○一○, Series $b ; \times-\times$, Series $c$. B, August I956 to October I957; - Series II; O-O, Series III; $\times-\times$, Series IV.

and fastened to plastic panels; these were exposed on a raft at a constant depth of about $3 \mathrm{ft}$. Several such series were put out at different times of the year. At appropriate intervals the material was brought in, the animals carefully cleaned, and each one measured. Growth was followed for several years.

The mean length of each size-group and the mean specific growth rates (increase in length per unit length per day) have been caculated and are plotted in Figs. I and 2. In some series a number of animals were lost, particularly during the later stages of exposure, a fact that introduces some bias into the comparisons. 


\section{THE RESULTS}

The first series was put out early in May 1955; it consisted of three size-groups of mean length $\mathrm{I} \cdot 9,2 \cdot 8$, and $4 \cdot \mathrm{I} \mathrm{mm}$., equivalent to first, second, and third year-groups on the shore (see p. 43I). In all these growth was rapid and continuous during the late spring and the summer months. By late August there was little difference between the mean sizes of the three groups, which were $5 \cdot 5,5 \cdot 7$, and $6 \cdot 0 \mathrm{~mm}$.

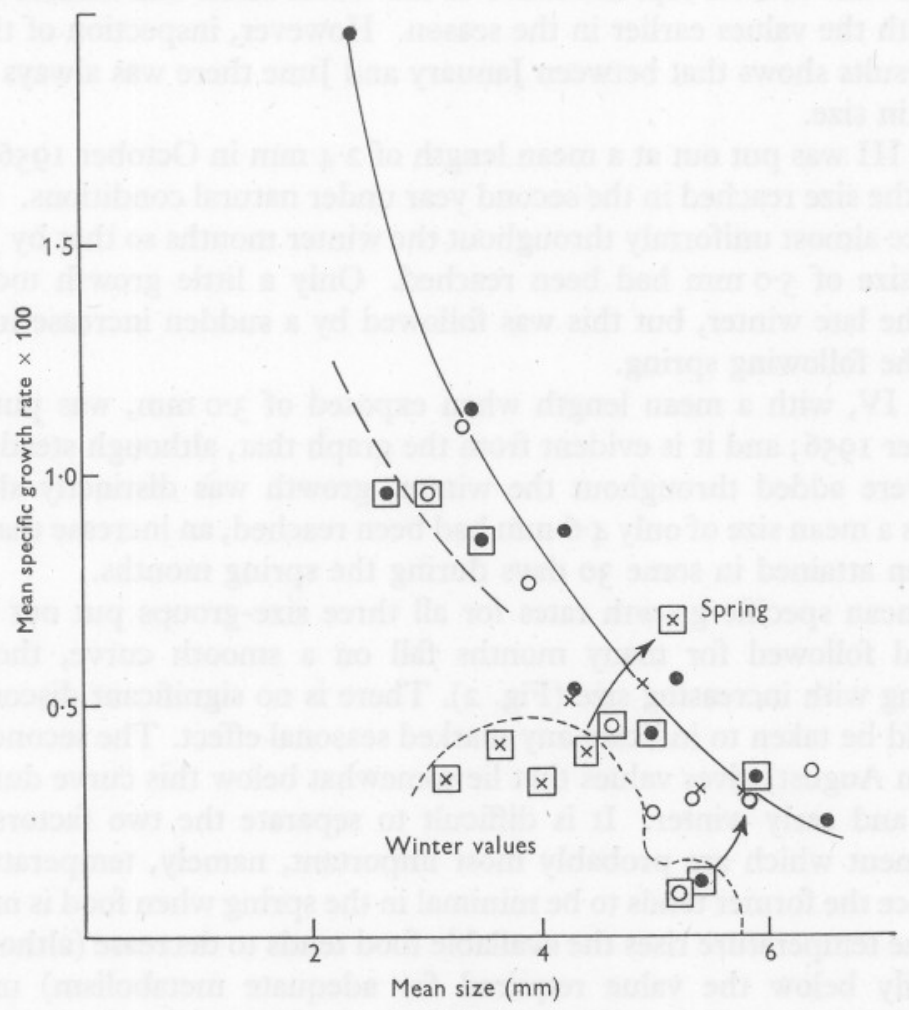

Fig. 2. The mean specific growth rate $\left(\frac{\Delta l}{\bar{l} . n}\right) \times 100$, of Verruca stroemia, for all series: symbols as in Fig. I, values from Fig. I B in squares.

During the following early winter growth was slow, but it must be remembered that the animals were approaching their maximum size. Between the end of November and February of the next year there was no increase in size in any of the groups, but growth was renewed in the spring of 1956 and continued very slowly during the following summer. By the end of the second summer all the groups had reached their maximum size of about $8 \mathrm{~mm}$. It is evident that under the experimental conditions, namely, exposure on a raft near the surface and freedom from epiphytic growth and mud, this sublittoral 
barnacle, which even extends into relatively deep inshore waters, grows rapidly. The maximum size is approached in only one season's growthbetween settlement in the spring and the following November.

A second series, its mean size $2 \cdot 2 \mathrm{~mm}$ (no smaller ones being available), was put out during the August of 1956. Growth took place rapidly and continued at about a uniform rate until early December when a size of $5.3 \mathrm{~mm}$ had been reached. During the following winter many of these animals were lost and the mean sizes are not representative of the whole series and cannot be compared with the values earlier in the season. However, inspection of the individual results shows that between January and June there was always a slight increase in size.

Series III was put out at a mean length of $2.4 \mathrm{~mm}$ in October 1956, that is again at the size reached in the second year under natural conditions. Growth took place almost uniformly throughout the winter months so that by January a mean size of $5.0 \mathrm{~mm}$ had been reached. Only a little growth took place during the late winter, but this was followed by a sudden increase in length during the following spring.

Series IV, with a mean length when exposed of $3.0 \mathrm{~mm}$, was put out in December 1956; and it is evident from the graph that, although steady increments were added throughout the winter, growth was distinctly slow. In 4 months a mean size of only $4.6 \mathrm{~mm}$ had been reached, an increase that would have been attained in some 30 days during the spring months.

The mean specific growth rates for all three size-groups put out in May 1955 and followed for many months fall on a smooth curve, the values decreasing with increasing size (Fig. 2). There is no significant discontinuity that could be taken to indicate any marked seasonal effect. The second series, started in August, gives values that lie somewhat below this curve during the autumn and early winter. It is difficult to separate the two factors of the environment which are probably most important, namely, temperature and food, since the former tends to be minimal in the spring when food is maximal, and as the temperature rises the available food tends to decrease (although not necessarily below the value required for adequate metabolism) until the autumnal diatom outburst. The lower values in Series II, nevertheless, may be ascribed to inadequate food supply or, much less likely, to the deleterious effects of higher summer temperatures in the surface water as affecting particularly the smaller animals. The midwinter values of this series are only some $50 \%$ of the mean specific growth rates of Series I at the same size, and since the temperatures at this season are approaching those of the spring and early summer, it seems that the reduced growth rate if related directly to the environment is a result of inadequate food supply. This suggestion is substantiated by the fact that in the following spring a growth rate somewhat greater than that of the first series is found. Series III follows a similar pattern, the values for the autumn and early winter falling into line with those for 
Series II (broken line); the midwinter values are again those of the first series and a return to the 'normal' is made in the following spring. Series IV was put out in December; the values are now initially very low, that is, throughout the winter, again supporting the hypothesis that food supply is a limiting growth factor at this time of the year. In the following late spring a much higher rate of growth was obtained at equivalent sizes than in Series I. This higher value in the spring and early summer in Series II and IV, and the fact that the effect is more marked in the smaller individuals, strengthens the suggestion that even the midsummer growth rates in Series I, although falling on a smooth curve, may be somewhat depressed by the higher summer temperatures or limited by food supply; however, loss of animals in the longer exposures tends to bias the results and the suggestion must be regarded as tentative.

The growth of individual animals was not followed on the shore. However, a large randomly taken population was measured during May and the frequency distribution plotted on probability paper. Three classes could be distinguished with mean lengths of $2.0,2.8$, and $4.0 \mathrm{~mm}$. These seem to correspond to three consecutive year-groups-the first having settled in the early spring of the current year and having by May reached $2.0 \mathrm{~mm}$, that is the size of the first exposures put out on the raft.

\section{DISCUSSION}

It is evident that $V$. stroemia follows a very similar growth pattern to several of the other species previously investigated. Settlement in the spring is followed by rapid growth; little increase in size takes place during the winter, but renewed growth is established in the following spring. The fact that animals exposed later in the year grow at almost the same rate as those put out in the spring at the same size suggests that there is no marked endogenous or seasonal rhythm per se. Growth appears to be directly related to conditions of environment, being rapid when there is abundant food. How far there is any seasonal change in growth rate in deep water, where the temperature range is small and food supply perhaps relatively so, is unknown. Indeed, it would be of considerable interest to have growth data from animals maintained in deep water under similar experimental conditions to the present series, in particular being kept free from encrusting organisms. Under these conditions any endogenous rhythm might be more easily recognized.

The rate of growth is very greatly increased under the experimental conditions and as with other species this may be ascribed in part to the greater availability of food in the surface layers and in part to the freedom from encrusting growths and mud-both common under natural conditions. The absence of the species from suitable substrata in shallow water cannot be ascribed to any deleterious effect of such an environment. 
It is now possible to compare the growth characters of several species measured under the partially controlled conditions of raft exposure. For such a comparison the effect of size may be eliminated by using the specific growth rate and by employing its value at what may be termed the half life period, taken as half the maximum size attained by a species, we may expect to eliminate the effect of age. The values for several species are shown in Table I.

\begin{tabular}{lcc} 
& TABLE 1 & Mean specific \\
\multicolumn{1}{c}{ Species } & $\begin{array}{c}\text { Maximum } \\
\text { size }(\mathrm{mm})\end{array}$ & $\begin{array}{c}\text { growth rate }(\times \text { roo }) \\
\text { at half size }\end{array}$ \\
Balanus balanoides & 25 & $\mathrm{I} \cdot 0$ \\
B. crenatus & 25 & $\mathrm{I} \cdot 3$ \\
B. balanus & 43 & $0 \cdot 9$ \\
Chthamalus stellatus & $\mathrm{IO}$ & $\mathrm{O} \cdot \mathrm{I}$ \\
Verruca stroemia & 8 & $\mathrm{I} \cdot \mathrm{O}$
\end{tabular}

The mean specific growth rates at half maximum size are, with the exception of Chthamalus stellatus, very similar, from which it may be assumed that the intrinsic metabolic activities are of the same order. Indeed, the apparent differences may well be the result of taking shell length as a measure of animal size and its rate of change. The value for $C$. stellatus is much lower than for the other species and while the above factor is again of importance a lower intrinsic metabolic rate is indicated. This agrees with the observations of Southward (1955) who found that over their optimal range the cirral beat of C. stellatus was slower than that of Balanus balanoides. However, unlike other species investigated, Chthamalus stellatus showed very little increase in growth rate when transferred to raft conditions; after an initial acceleration immediately following the change, the rate returned to a value little different from that on the shore (Barnes, 1956). Perhaps greater general stimulation - such as would be provided under natural conditions by wave action or experimentally by water currents-is necessary for the full metabolic activity of C. stellatus.

\section{SUMMARY}

Data are presented on the growth rate of Verruca stroemia under natural conditions and when exposed continuously and cleaned repeatedly. Several series exposed at different times of the year were followed.

Rapid growth takes place (under raft conditions) following settlement; the maximum size is virtually reached in one season's growth between spring and early winter. There is little growth in midwinter.

Differences between the mean specific growth rates of the various series can be ascribed to differences in the availability of food.

The question is discussed as to whether there is any seasonal rhythm; the evidence indicates that no marked rhythmic pattern of growth exists. 
Observations on deep-water populations would be of value for comparison and to unmask any relatively weak rhythmic growth.

The mean specific growth rates at half their maximum size are compared for several species-Balanus balanoides, B. crenatus, B. balanus, Chthamalus stellatus and Verruca stroemia; it is similar for all species except Chthamalus stellatus. The high level barnacle may require stimulation such as is provided by wave action to elicit full metabolic activity.

\section{REFERENCES}

BARNes, H., 1952-53. The effect of light on the growth rate of two barnacles Balanus balanoides (L.) and B. crenatus Brug. under conditions of total submergence. Oikos, Vol. 4. pp. IO4-II.

- 1956. The growth rate of Chthamalus stellatus (Poli). F. mar. biol. Ass. U.K., Vol. 35, pp. 355-6r.

BARNES, H. \& BARNES, M., I954. The general biology of Balanus balanus (L.) Da Costa. Oikos, Vol. 5, pp. 63-76.

— 1956. The general biology of Balanus glandula Darwin. Pacif. Sci., Vol. Io, pp. 415-22.

Barnes, H. \& Powell, H. T., 1953. The growth of Balanus balanoides (L.) and B. crenatus Brug. under varying conditions of submersion. F. mar. biol. Ass. U.K., Vol. 32, pp. 107-28.

BRoch, H., 1924. Cirripedia Thoracica von Norwegen und dem Norwegischen Nordmeere. Skr. VidenskSelsk., Christ., Bd. I, No. 17, I2I pp.

CRISP, D. J., 1954. The breeding of Balanus porcatus (Da Costa) in the Irish Sea. F. mar. biol. Ass. U.K., Vol. 33, pp. 473-96.

Darwin, C. R., I854. A Monograph on the Sub-class Cirripedia. 684 pp. London: Ray Soc.

Kolosvary, G. 1947. Die Balaniden der Adria. Ann. hist.-nat. Mus. hung., Vol. 40, pp. I-88.

Nilsson-Cantell, C. A., I938. Cirripedes from the Indian Ocean in the collection of the Indian Museum, Calcutta. Mem. Indian Mus., Vol. I3, Part I, 8I pp.

SCHAPER, P., I922. Beiträge zur Kenntnis der Cirripedia Thoracica der Nord- und Ostsee. Wiss. Meeresuntersuch., Abt. Kiel, N.F., Bd. I9, pp. 21 I-50.

SouthwARD, A. J., I955. On the behaviour of barnacles. I. The relation of cirral and other activities to temperature. F. mar. biol. Ass. U.K., Vol. 34, pp. 403-22.

Stephensen, K., I929. Cirripedia (excl. Rhizocephala). Zoology of the Faroes, Vol. 2, pt. I, No. 27,9 pp.

— 1933. Ranke fødder eller Cirripedier. Danm. Fauna, No. 38, pp. 57-158.

WeltneR, W., 1900. Die Cirripedien der Arktis. Fauna arct., fena, Bd. I, pp. 287-312. 